\title{
Recycled ejecta modulating Strombolian explosions
}

\author{
Antonio Capponi $^{1,2} \cdot$ Jacopo Taddeucci $^{2} \cdot$ Piergiorgio Scarlato $^{2} \cdot$ \\ Danilo M. Palladino ${ }^{3}$
}

Received: 23 September 2015 / Accepted: 27 January 2016/Published online: 15 February 2016

(C) The Author(s) 2016. This article is published with open access at Springerlink.com

\begin{abstract}
Two main end-members of eruptive regimes are identified from analyses of high-speed videos collected at Stromboli volcano (Italy), based on vent conditions: one where the vent is completely clogged by debris, and a second where the vent is open, without any cover. By detailing the vent processes for each regime, we provide the first account of how the presence of a cover affects eruptive dynamics compared to open-vent explosions. For clogged vents, explosion dynamics are controlled by the amount and grain size of the debris. Fine-grained covers are entirely removed by explosions, favouring the generation of fine ash plumes, while coarse-grained covers are only partially removed by the explosions, involving minor amounts of ash. In both fine- and coarse-grained cases, in-vent ground deformation of the debris reflect variations in the volumetric expansion of gas in the conduit, with rates of change of the deformation comparable to ground inflation related to pre-burst conduit pressurization. Eruptions involve the ejection of relatively slow and cold
\end{abstract}

Editorial responsibility: P-S Ross

Electronic supplementary material The online version of this article (doi:10.1007/s00445-016-1001-z) contains supplementary material, which is available to authorized users.

Antonio Capponi

a.capponi@lancaster.ac.uk

1 Lancaster Environment Centre, Lancaster University, Lancaster LA1 4YQ, UK

2 Istituto Nazionale di Geofisica e Vulcanologia, Via di Vigna Murata 605, 00143 Rome, Italy

3 Dipartimento di Scienze della Terra, Sapienza-Università di Roma, Rome, Italy bombs and lapilli, and debris is observed to both fall back into the vent after each explosion and to gravitationally accumulate between explosions by rolling down the inner crater flanks to produce the cover itself. Part of this material may also contribute to the formation of a more degassed, crystallized and viscous magma layer at the top of the conduit. Conversely, open-vent explosions erupt with hotter pyroclasts, with higher exit velocity and with minor or no ash phase involved.

Keywords Strombolian eruptions · Vent processes · Eruption dynamics $\cdot$ Plume dynamics $\cdot$ Ejection velocity $\cdot$ High-speed video

\section{Introduction}

Strombolian eruptions are characterized by relatively mild, impulsive releases of gas and pyroclasts that typically last a few to tens of seconds and eject a gas-particle mixture to several tens to hundreds of metres in height (e.g. Houghton and Gonnermann 2008; Cashman and Sparks 2013; Taddeucci et al. 2015). Eruptions result from the arrival and burst of overpressured gas pockets (slugs) at the free-surface (Chouet et al. 1974; Blackburn et al. 1976; Parfitt 2004; Houghton and Gonnermann 2008). This widely accepted scenario is supported by a large body of literature focused on understanding the mechanism behind explosions at Stromboli volcano (Aeolian Islands, Italy) via, for example, interpretation of seismic and infrasonic data (e.g. Vergniolle et al. 1996; Chouet et al. 2003, 2008; Marchetti and Ripepe 2005), experimental studies (e.g. James et al. 2004, 2006, 2008; Lane et al. 2013), and field observations (e.g. Chouet et al. 1974; Blackburn et al. 1976; Ripepe et al. 1993, 2005; Patrick et al. 2007; Harris et al. 2012; Taddeucci et al. 2012a, b; Gaudin et al. 2014; Bombrun et al. 2015). 
However, none of these studies have focused on detailing how the gas is physically released into the atmosphere, i.e. the vent processes.

Increasing textural, experimental and field evidence suggests that the Strombolian paradigm of slugs ascending and bursting in a rheologically uniform melt is too simplistic, pointing instead to the coexistence of melts with different rheological properties in the shallower conduit (Gurioli et al. 2014; Leduc et al. 2015). Cooling and degassing of the uppermost part of the magma column may lead to the generation of a more viscous and evolved magma layer in which a gas pocket bursts (Gurioli et al. 2014). The properties and thickness of this layer may have an impact on the eruptive dynamics, to cause variations in explosion intensity and style (Lautze and Houghton 2005, 2006). Textural and geochemical analyses of ejected pyroclasts at Stromboli support the coexistence of melts with contrasting rheologies (Lautze and Houghton 2005; D'Oriano et al. 2011; Colò et al. 2010), leading to magma mingling during the ascent and burst of a slug (Gurioli et al. 2014; Leduc et al. 2015).

Recent experimental investigation endorses the presence of a plug (Fig. 1), demonstrating how the interaction of an ascending slug with a high-viscosity plug heavily affects fluid dynamic processes in the conduit and explaining some of the key phenomena observed at Stromboli, such as the eruptive pulses and sub-pulses and the occurrence of mingled pyroclasts (Del Bello et al. 2015). The presence of a plug also affects the degree of slug overpressurization, leading to an increase in the explosivity of Strombolian eruptions (Del Bello et al. 2015).

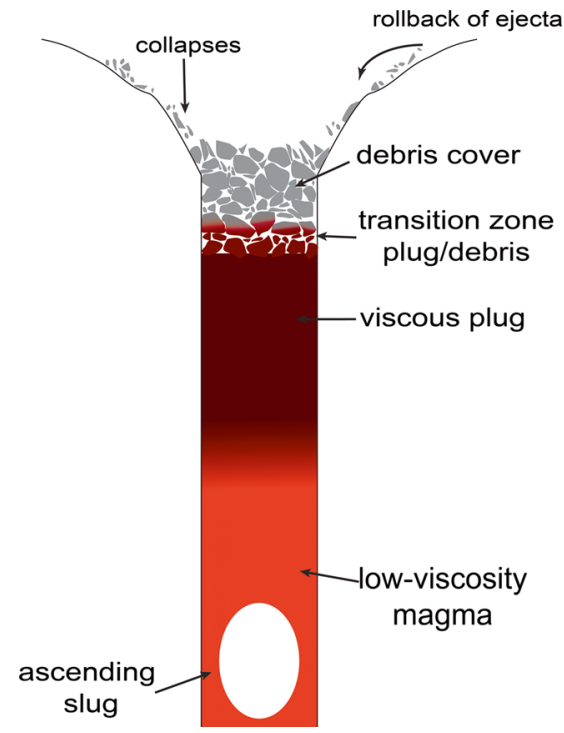

Fig. 1 Conceptual sketch of the volcanic conduit, in which a gas slug ascends through a rheologically stratified magma column, and the vent clogged by debris. The debris cover is generated by fallback of pyroclasts into the vent and collapses of the conduit wall; a transition zone exists between the degassed layer at the top of the magma column (plug) and the debris cover filling the vent
A second surficial layer may be also present due to temporary blockage of the vent due to backfilling of the conduit (Fig. 1). This has been proposed to result from collapses and slumping of the conduit wall, by rollback of erupted pyroclasts and lithic clasts into the vent (McGetchin et al. 1974), or magma draining back into the conduit, favouring the generation of ash plumes due to grinding of the back-fill clasts during the explosive event (Patrick et al. 2007). In light of these new findings, understanding the dynamics and evolution of vent processes during explosions at Stromboli has gained more importance if we are to unravel the complete mechanism responsible for the persistent but extremely variable explosive activity, such as that classically observed at Stromboli. In this paper, we investigate how the presence of a debris cover affects the style of Strombolian eruptions through analysis of high-speed videos acquired at Stromboli. We identify two main eruptive regimes depending on the vent conditions (i.e. open vent vs. clogged vent) and show how the nature and amount of a debris cover strongly modify the vent processes and, eventually, explosion dynamics, magnitude and pyroclasts ejection velocity.

\section{Terminology}

Explosions at Stromboli, although relatively mild and of short duration, can be very complex in terms of both dynamics and evolution. An individual "explosion" is characterized by multiple, second-long "pulses" and sub-second-long "subpulses", each pulse being characterized by the ejection of particles at similar velocities which then decrease in time (Taddeucci et al. 2012a; Gaudin et al. 2014; Bombrun et al. 2015). In addition we can observe multiple emission points during a single event. Thus we use the term "vent" to indicate an area of emission points active during a single event.

\section{Eruptions at Stromboli}

Stromboli is the northernmost island of the Aeolian arc. It covers an area of $\sim 12.2 \mathrm{~km}^{2}$, with its summit at $924 \mathrm{~m}$ above sea level (a.s.1.). The current volcanic activity has persisted for at least 1400 years (Rosi et al. 2000) in the constantly evolving crater terrace located at $\sim 800 \mathrm{~m}$ a.s.l. (Washington 1917; Rosi et al. 2000; Harris and Ripepe 2007), comprising three vent areas within the North-East (NEC), Central (CC) and SouthWest (SWC) craters (Fig. 2). This typical state of explosive activity at Stromboli is usually classified as "normal activity" and consists of recurrent mild explosions and continuous degassing (Barberi et al. 1993; Harris and Ripepe 2007; Burton et al. 2007), with inter-explosion time intervals of $10-10^{3} \mathrm{~s}$, and ejecting a gas/pyroclast mixture at a few tens to hundreds of metres of height (e.g. Houghton and 
Fig. 2 (a) View of the crater terrace at Stromboli from Pizzo Sopra la Fossa on September 2, 2008. $S W, C$, and $N E$ mark the South-West, Central and NorthEast vent areas, respectively, while numbers mark individual vents in each vent area. (b) Closeup of the active vents imaged during the data acquisition at the North-East $(N E)$ and South-West $(S W)$ vent areas (satellite image courtesy of Jeff Schmaltz, MODIS Rapid Response Team, NASA GSFC, NASA Earth Observatory)

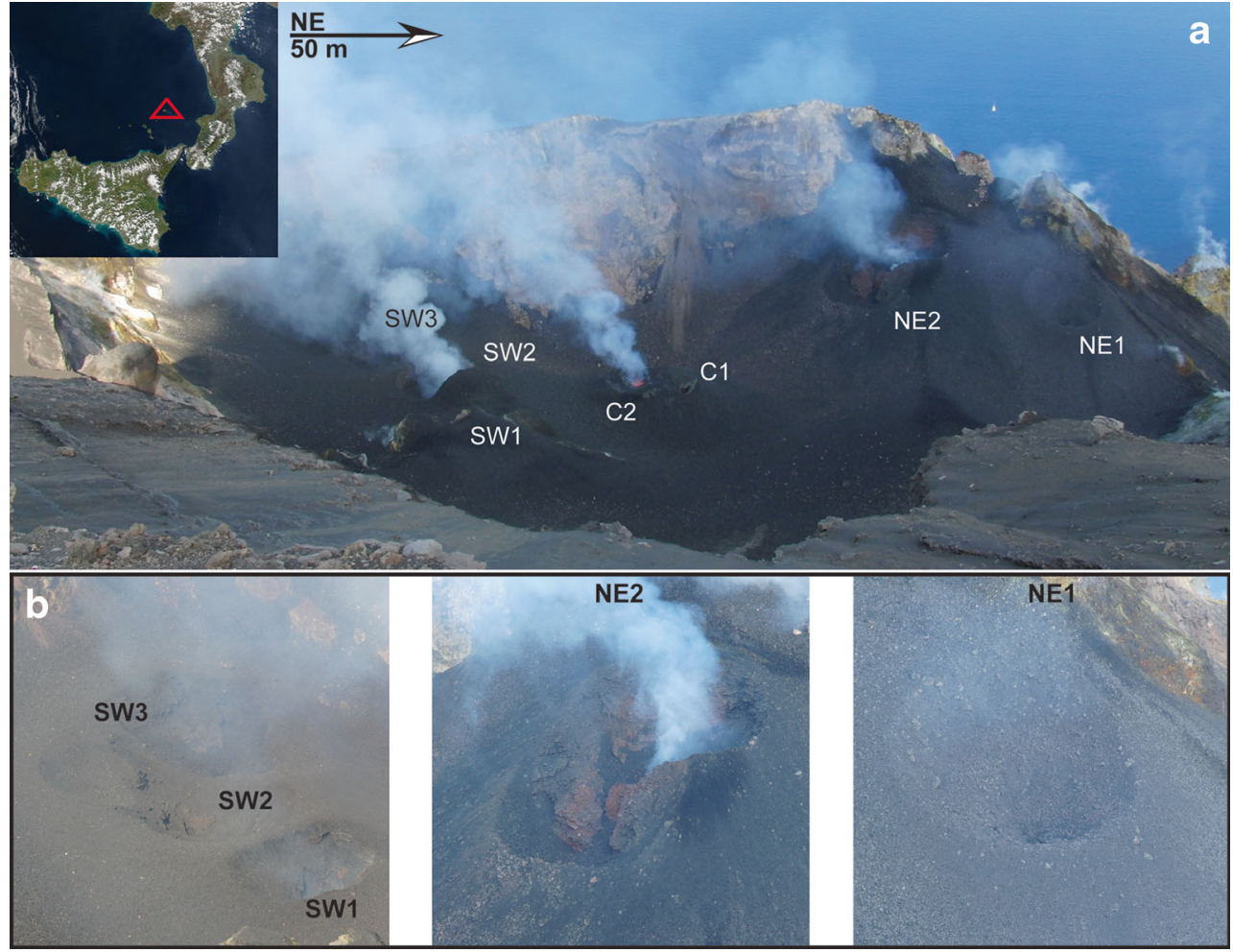

Gonnermann 2008; Cashman and Sparks 2013; Taddeucci et al. 2013a). The "normal activity" is characterized by three main types of explosions: Type 1 are ballistic-dominated events, with minor occurrence or absence of an ash plume; Type 2 events involve a noticeable ash plume and can be either ballistic-rich (Type 2a) or ballistic-poor (Type 2b) (Patrick et al. 2007). Recently, this classification has been expanded by the introduction of a new eruption type, Type 0, which involves gas-dominated jets, characterized by the ejection of few and small juvenile pyroclasts, together with recycled material at high velocities (Leduc et al. 2015).

\section{Methods}

\section{Equipment and data collection}

Data presented here were obtained using a high-speed camera NAC HotShot 512SC. This self-contained high-speed video system records videos using a C-MOS monochromatic sensor sensitive into the near-infrared spectral region (down to about $0.1 \mu \mathrm{m}$ ), so that hot particles can be distinguished visually from cold particles by their lighter tone. At Stromboli the camera was operated at variable frame rates from 250 to 500 frames per second (fps), a resolution of $512 \times 512$ pixels with an 8-bit greyscale, bit density of 10 bits, and variable exposure times. The $4 \mathrm{~GB}$ on-board memory allowed $32.6 \mathrm{~s}$ of recording time at $500 \mathrm{fps}$, and $65.2 \mathrm{~s}$ at $250 \mathrm{fps}$.
The camera was tripod-mounted at Pizzo Sopra la Fossa, from where a complete view of the crater terrace is available (Fig. 2). This location was $288 \mathrm{~m}$ away and $165 \mathrm{~m}$ above the NE crater, $293 \mathrm{~m}$ away and $182 \mathrm{~m}$ above the SW crater, and the camera was tilted downward towards the vent of interest at an angle of $32^{\circ}$. The distance from the vents at the time of filming was determined by a laser telemeter (with a resolution of $\pm 0.5 \mathrm{~m}$ ) and used to scale image size. A $300 \mathrm{~mm}$ professional lens was used, with a resulting field of view of $1.5^{\circ}$. Depending on the vent involved, each pixel had a width between 1.52 and $1.60 \mathrm{~cm}$. All videos were acquired during daylight.

The high-speed camera data used in this study were collected during three field missions for a total of 6 days of shooting at the NE and SW craters zone: 4 and 5 September 2008, 17-19 June 2009 and 27 October 2009. A total of 49 explosions were recorded: 21 were from the NE crater and 28 from the SW crater. These covered a wide range of eruption styles, i.e.: ballistic-poor, ash-free and gas-dominated explosions (Type 0), ballistic-rich and ash-free explosions (Type 1), ash- and ballistic-rich explosions (Type 2a), ash-rich ballisticfree explosions (Type $2 b$ ). Each video covers a single vent, but occasionally - depending on the camera position-multiple active vents were involved simultaneously. In both of the crater zones several vents were active, which we refer to as NE1, NE2 and SW1, SW2, SW3 (Fig. 2, Table 1).

In addition, we use one example from the SW crater obtained on May 20, 2013, using a FLIR SC640 thermal camera 
Table 1 Parameters (vent location, duration, maximum ejection velocity, vent condition and number of measured pyroclasts) for each explosion imaged by the high-speed camera

\begin{tabular}{|c|c|c|c|c|c|c|c|c|}
\hline Explosion & Date & GMT & Vent & Duration (s) & FPS & $\mathrm{V} \max (\mathrm{m} / \mathrm{s})$ & Vent condition & $N$ \\
\hline 1 & 04/09/2008 & $12: 20$ & NE1 & $>30 \mathrm{~s}$ & 500 & $62.94 \pm 3.3$ & coarse-grained cover & 284 \\
\hline 2 & 04/09/2008 & $12: 33$ & NE1 & $4 \mathrm{~s}$ & 500 & $50.07 \pm 3.7$ & coarse-grained cover & 286 \\
\hline 3 & 04/09/2008 & $13: 30$ & NE1 & $>30 \mathrm{~s}$ & 500 & $69.15 \pm 12.6$ & coarse-grained cover & 606 \\
\hline 4 & 04/09/2008 & $11: 00$ & NE2 & $15 \mathrm{~s}$ & 500 & $188.74 \pm 10.3$ & open & 398 \\
\hline 5 & 04/09/2008 & $11: 20$ & NE2 & $6 \mathrm{~s}$ & 500 & $323.14 \pm 74$ & open & 336 \\
\hline 6 & 04/09/2008 & $11: 36$ & NE2 & $>30 \mathrm{~s}$ & 500 & $256.45 \pm 10.1$ & open & 949 \\
\hline 7 & 04/09/2008 & $14: 37$ & SW3 & $13 \mathrm{~s}$ & 500 & $37.87 \pm 10.4$ & coarse-grained cover & 232 \\
\hline 8 & 04/09/2008 & $16: 55$ & SW1 & $>30 \mathrm{~s}$ & 500 & - & coarse-grained cover & - \\
\hline 9 & 05/09/2008 & $10: 20$ & $\mathrm{SW} 1+2$ & $10 \mathrm{~s}$ & 500 & $19.28 \pm 1.7$ & fine-grained cover & 131 \\
\hline 10 & 05/09/2008 & $10: 39$ & $\mathrm{SW} 1+2$ & $8 \mathrm{~s}$ & 500 & $19.12 \pm 0.9$ & fine-grained cover & 37 \\
\hline 11 & 05/09/2008 & $10: 45$ & $\mathrm{SW} 1+2$ & $20 \mathrm{~s}$ & 500 & $16.58 \pm 0.8$ & fine-grained cover & 237 \\
\hline 12 & 05/09/2008 & $11: 13$ & $\mathrm{SW} 1+2$ & $12 \mathrm{~s}$ & 500 & $21.1 \pm 2.6$ & fine-grained cover & 117 \\
\hline 13 & 05/09/2008 & $11: 51$ & $\mathrm{SW} 1+2+3$ & $25 \mathrm{~s}$ & 250 & $19.07 \pm 3.3$ & fine-grained + open & 167 \\
\hline 14 & 05/09/2008 & $12: 03$ & $\mathrm{SW} 1+2+3$ & $>56 \mathrm{~s}$ & 250 & $28.6 \pm 1.1$ & fine-grained + open & 656 \\
\hline 15 & 05/09/2008 & $12: 20$ & $\mathrm{SW} 1+2+3$ & $25 \mathrm{~s}$ & 250 & $17.18 \pm 2.05$ & fine-grained + open & 466 \\
\hline 16 & $17 / 06 / 2009$ & 09:xx & SW1 & $\sim 60 \mathrm{~s}$ & 250 & $388.02 \pm 70.7$ & open & 1887 \\
\hline 17 & $17 / 06 / 2009$ & $09: 57: 23$ & NE1 & $>30 \mathrm{~s}$ & 500 & - & - & - \\
\hline 18 & $17 / 06 / 2009$ & $11: 16: 30$ & SW1 & $>30 \mathrm{~s}$ & 500 & $152.21 \pm 11.3$ & open & 478 \\
\hline 19 & $17 / 06 / 2009$ & $11: 35: 42$ & SW1 & $>30 \mathrm{~s}$ & 500 & $205.81 \pm 4$ & partially covered & 821 \\
\hline 20 & $17 / 06 / 2009$ & $12: 02: 20$ & SW1 & $>30 \mathrm{~s}$ & 500 & $259 \pm 6.6$ & partially covered & 3370 \\
\hline 21 & $17 / 06 / 2009$ & $12: 25: 13$ & SW1 & $>30 \mathrm{~s}$ & 500 & $230 \pm 2.2$ & open & 4001 \\
\hline 22 & $17 / 06 / 2009$ & $13: 05: 17$ & SW1 & $\sim 32 \mathrm{~s}$ & 500 & $172 \pm 13.7$ & open & 2425 \\
\hline 23 & $17 / 06 / 2009$ & $13: 17: 39$ & $\mathrm{SW} 1+2$ & $22 \mathrm{~s}$ & 500 & $26.08 \pm 1$ & open + coarse-grained & 116 \\
\hline 24 & $17 / 06 / 2009$ & $13: 36: 55$ & $\mathrm{SW} 1+2$ & $7 \mathrm{~s}$ & 500 & - & coarse-grained cover & - \\
\hline 25 & $17 / 06 / 2009$ & $14: 14: 58$ & SW1 & $>30 \mathrm{~s}$ & 500 & $224.84 \pm 12.8$ & partially covered & 667 \\
\hline 26 & $17 / 06 / 2009$ & $14: 30: 28$ & SW1 & $\sim 32 \mathrm{~s}$ & 500 & $181.96 \pm 12.9$ & open & 1089 \\
\hline 27 & $17 / 06 / 2009$ & $14: 41: 44$ & SW1 & $20 \mathrm{~s}$ & 500 & $138.76 \pm 17.4$ & open & 538 \\
\hline 28 & $17 / 06 / 2009$ & $15: 26: 50$ & SW1 & $26 \mathrm{~s}$ & 250 & $409.82 \pm 6.9$ & open & 1802 \\
\hline 29 & $18 / 06 / 2009$ & $11: x x$ & NE2 & $20 \mathrm{~s}$ & 500 & $74.7 \pm 9$ & coarse-grained cover & 283 \\
\hline 30 & $18 / 06 / 2009$ & $10: 34: 50$ & NE2 & $7 \mathrm{~s}$ & 500 & $120.85 \pm 2.6$ & coarse-grained cover & 129 \\
\hline 31 & $18 / 06 / 2009$ & $10: 59: 20$ & NE2 & $10 \mathrm{~s}$ & 500 & $53.9 \pm 2.5$ & coarse-grained cover & 174 \\
\hline 32 & $18 / 06 / 2009$ & 12:06:xx & NE2 & $7 \mathrm{~s}$ & 500 & - & - & - \\
\hline 33 & $19 / 06 / 2009$ & 09:30:xx & NE1 & $17 \mathrm{~s}$ & 500 & $367.90 \pm 1.2$ & open & 351 \\
\hline 34 & 19/06/2009 & $10: 48: 29$ & NE1 & $10 \mathrm{~s}$ & 500 & $226.22 \pm 17$ & open & 599 \\
\hline 35 & 19/06/2009 & $11: 04: 46$ & NE1 & $25 \mathrm{~s}$ & 500 & $365.49 \pm 12.1$ & open & 599 \\
\hline 36 & $19 / 06 / 2009$ & $11: 26: 08$ & NE1 & $20 \mathrm{~s}$ & 500 & $316.93 \pm 29.6$ & open & 477 \\
\hline 37 & 19/06/2009 & 12:04:41 & NE1 & $18 \mathrm{~s}$ & 500 & $168.89 \pm 6.5$ & open & 2706 \\
\hline 38 & 19/06/2009 & $12: 15: 30$ & NE1 & $12 \mathrm{~s}$ & 500 & $197.09 \pm 1.6$ & open & 708 \\
\hline 39 & $19 / 06 / 2009$ & $12: 39: 57$ & NE1 & $12 \mathrm{~s}$ & 500 & $166.46 \pm 13.5$ & open & 644 \\
\hline 40 & 19/06/2009 & 13:01:34 & NE1 & $15 \mathrm{~s}$ & 500 & $268.71 \pm 7.8$ & open & 624 \\
\hline 41 & $19 / 06 / 2009$ & 13:18:38 & NE1 & $11 \mathrm{~s}$ & 500 & $127.44 \pm 2.2$ & open & 1616 \\
\hline 42 & $19 / 06 / 2009$ & $13: 32: 34$ & NE1 & $20 \mathrm{~s}$ & 500 & $324.24 \pm 10.2$ & open & 769 \\
\hline 43 & 27/10/2009 & $11: 38: 37$ & SW1 & $?$ & 500 & - & - & - \\
\hline 44 & 27/10/2009 & $11: 53: 21$ & SW1 & $11 \mathrm{~s}$ & 500 & $370 \pm 3$ & open & 1250 \\
\hline 45 & 27/10/2009 & $12: 03: 35$ & SW1 & $8 \mathrm{~s}$ & 500 & $199.12 \pm 2.5$ & open & 873 \\
\hline 46 & 27/10/2009 & $12: 23: 15$ & SW1 & $9 \mathrm{~s}$ & 500 & $337 \pm$ & open & 494 \\
\hline 47 & 27/10/2009 & $12: 40: 02$ & SW1 & $5 \mathrm{~s}$ & 500 & $190.47 \pm 17.7$ & open & 411 \\
\hline 48 & 27/10/2009 & $13: 32: 51$ & SW1 & $6 \mathrm{~s}$ & 500 & $367 \pm 18.2$ & open & 1405 \\
\hline 49 & 27/10/2009 & $13: 58: 55$ & SW1 & $13 \mathrm{~s}$ & 500 & $405 \pm 28.2$ & open & 1479 \\
\hline
\end{tabular}

FPS frames per second, $N$ number of measured pyroclasts (total $N$ covering all events $=37,687$ particles manually tracked) 
$(7.5-13 \mu \mathrm{m})$ recording at $50 \mathrm{fps}$ with a $640 \times 480$ pixel resolution. We also include four examples from NE crater activity filmed on 4 September 2008 , at $300 \mathrm{fps}$ with a $512 \times 384$ pixel resolution using a Casio Exilim camcorder. A few visual observations from other field campaigns are also referred to in the text.

\section{Analysis}

The first analysis step was a qualitative description of the videos. This initial analysis allowed us first to evaluate the overall quality of the videos in terms of visibility, sharpness, focus, and disturbances from vents active outside of the camera field of view. Among all of the videos, two were discarded because the files were corrupt, and two because the erupting vent was outside of the field of view. We next described each explosion in terms of: (1) overall particle size and velocity trends, (2) variations in jet orientation, (3) multiple ejection pulses within a single explosion, (4) the presence or absence of plumes, (5) the abundance of juvenile vs. accidental pyroclasts, and (6) any additional processes observed.

\section{Explosion duration}

Explosion duration was measured using the onset of the explosion as defined by the time at which the first particle is observed in the ballistic-rich explosions, or the first ash emission in the ash-rich events. The on-board memory and the fps settings of the camera limit the maximum recording time. Thus, only for 10 cases it was impossible to define the end of the explosion, due to the memory limit or the view of the vent being obscured by the presence of ash.

\section{Ejection velocities}

Quantitative measurements were performed using ImageJ, a public domain Java-based image processing programme (Abramoff et al. 2004), and the MTrackJ plug-in (Meijering et al. 2012). The MTrackJ plug-in allows manual tracking of moving objects within an image stack, and was used for parameterizing the ejection velocity of pyroclasts. Velocities were manually measured for centimetre-sized clasts, where selected particles exiting the vent were tracked for 4-10 frames. One or more new trajectories were initiated every 24 frames, covering the fastest visible pyroclasts. For each trace we measured the mean velocity $(\mathrm{m} / \mathrm{s})$ over all traced points forming the trajectory (and standard deviation, $\sigma$ ). All the measurements were made as close as possible to the vent. The ejection velocity was measured for all explosions ejecting clearly traceable particles. Out of 45 videos, 15 were selected as the most representative of the overall variability and were processed for their entire duration so as to be used as reference models, and covered each vent in each of the measurement day. For the remaining videos, velocity measurements focused on the onset of the explosion and key moments, selected based on qualitative observations (e.g. peak of activity, onset of multiple pulses). For each explosion, we measured a minimum of 37 up to a maximum of 4001 pyroclasts (Table 1).

\section{Activity description}

Based on specific vent conditions at the time of the video acquisition, we identified two end-members of eruptive regimes, depending on the state of the vent before an explosion: one where the vent was completely obstructed by debris (ranging from blocks to ash in size), and a second where the vent was open, without any cover. In between, explosions featuring processes common to both groups occurred.

\section{Activity at clogged vents}

In the first regime, all explosions were preceded by the uplift of the debris cover, but the type of debris comprising the vent infill resulted in remarkably different processes. With coarse debris, once the cover reached a critical degree of inflation (Fig. 3a, b), several breaches between the blocks were formed, from which jets of relatively cold, fine particles started to propagate. Ash emission from the breaches produced an ash plume (Fig. 3c, d), whose height often exceeded the camera field of view ( 9 m, Fig. 3e), followed closely by the ejection of juvenile pyroclasts (Fig. 3f). In some cases, this initial pulse managed to remove only part of the debris from the vent. The following jets managed to make their way through the remaining blocks and to propagate from a small localized point of emission. These were collimated jets that reached a height exceeding the limit of the camera field of view, alternating with poorly collimated ones (Video 1).

Slumping of the inner crater walls and rollback of ejecta down the inner crater slopes towards the vent was evident. In a few cases we observed the formation of a new, very small and localized emission point near the main one, characterized by continuous gas and pyroclast emission reaching heights well within the camera field of view $(\leq 9 \mathrm{~m})$. Initial ejection velocities reached up to $63 \pm 3 \mathrm{~m} / \mathrm{s}$, with few velocity fluctuations, followed by rapid velocity pulses with occasional fluctuations and increasing velocities. Emissions from secondary points reached velocities up to $\sim 70 \mathrm{~m} / \mathrm{s}$, while the shortest and weakest pulses had an average velocity of $<30 \mathrm{~m} / \mathrm{s}$, featuring several velocity peaks up to $50 \pm 4 \mathrm{~m} / \mathrm{s}$. In contrast, when the initial pulse was energetic enough to entrain and clear-out all the debris in the vent, the explosions involved the ejection of a 
Fig. 3 Vents with a coarsegrained debris cover: representative still-frames of an explosion at the NE1 vent. Red polylines highlight the debris profile before (a) and after (b) the ground inflation preceding the explosion (c), with the dashed line representing the initial lowest position. An ash plume, accompanied by ejection of juvenile (brighter tones) and few accidental (darker tones) pyroclasts $(\mathbf{d}-\mathbf{e})$, is followed by collimated jets of pyroclasts (f)

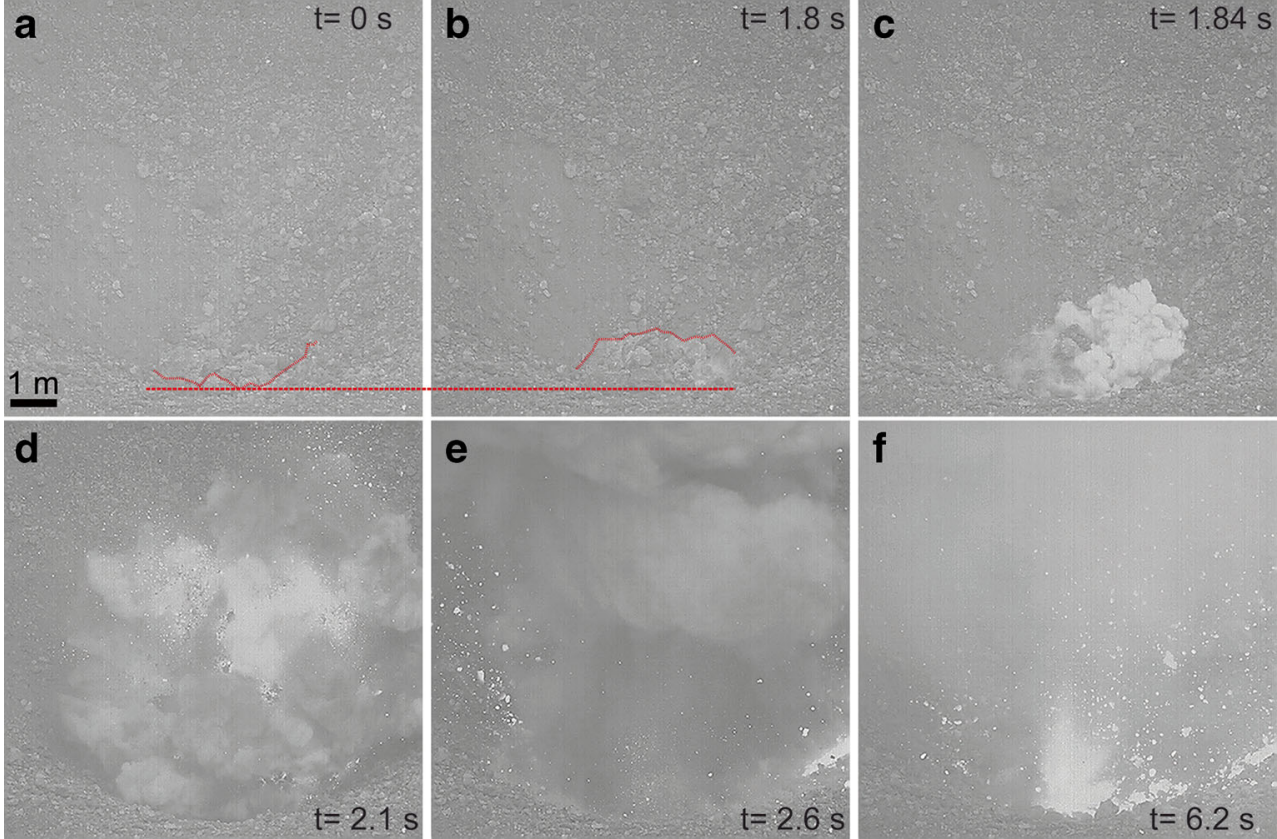

mixture of juvenile and recycled, ash- to block-sized, pyroclasts (Video 2).

The inflation process that preceded these explosions lasted for up to tens of minutes, and was followed by subsequent deflation (Video 3). These vent cover motions reach vertical displacements up to $1.9 \mathrm{~m}$, with velocities up to $0.91 \mathrm{~m} / \mathrm{s}$ where debris doming accelerated nonlinearly in the few seconds preceding an explosion (Figs. 3a, b and 4).

For vents covered by fine particles, explosions were preceded by a slow and uniform expansion of the cover, until a sudden increase in the expansion velocity led to a breach in its central section from which jets began to propagate (Fig. 5a, b). These jets involved gas, ash and lapilli-sized pyroclasts emission, with few block-sized pyroclasts, and the development of a conspicuous ash plume, which often visually obscured many of the lapilli-sized pyroclasts. Occasionally, the fine-grained debris was displaced en-masse and its collapse triggered a pyroclastic density current that travelled for some tens of metres away from the vent (Fig. 6, Video 4). The explosions continued with an initial gas thrust phase and the ejection of juvenile pyroclasts and lithics, but the high-concentration of ash made it difficult to impossible to discern pulses, except for powerful ones when hot material overtook the front of the plume. Sometimes, falling of veils of ash seemed to mark the end of the explosion (Fig. 5c), only for ejection of juvenile and lithic clasts to resume from the same emission point, often along with the emission of a conspicuous ash plume from a new emission point within the vent or from a nearby vent (Fig. 5d, Video 5). Despite a vigorous gas thrust phase, these explosions were characterized by low ejection velocities, with a maximum of $21 \pm 3 \mathrm{~m} / \mathrm{s}$, and lasted from a minimum of $\sim 8$ up to 20 s. All explosions were preceded, and followed, by rolling of blocks and sliding of finer material down the inner crater slopes and towards the vent.

\section{Activity at open vents}

Vents that were clear of debris displayed a faint glow and the emission of fume. In these cases, ballistic-dominated (Type 1) explosions occurred, with minor or no associated ash phase. All explosions began with a diffuse spray of a few hot pyroclasts, exiting the vent and followed by more heavily loaded pulses of coarser pyroclasts (a similar behaviour for Type 1 explosions was also observed by Harris et al. 2012), occasionally interspersed by sub-pulses (Fig. 7). Often, the ejection of metre-sized spatter also occurred. These molten clots were flattened on landing on the inner crater walls. Often, ejecta fell back around and into the vent, and then seemed to be reworked and ejected again in the following sub-pulses. The explosions lasted between $5 \mathrm{~s}$ and $>33 \mathrm{~s}$. When it was possible to observe the whole explosions, a gradual decrease in the amount of ejected material over time was evident, mirrored by a well-defined coda of decreasing pyroclast velocity (Video 6). The average velocities ranged between 20 and $50 \mathrm{~m} / \mathrm{s}$, featuring tens of high velocity peaks: usually $<250 \mathrm{~m} / \mathrm{s}$ (Fig. 8a, b), but in some cases exceeding $300 \mathrm{~m} / \mathrm{s}$, with an observed maximum of $410 \pm 7 \mathrm{~m} / \mathrm{s}$ (Explosion 28). These pulses and sub-pulses occurred so frequently that their individual velocity decay trends merged together. This explosive behaviour was characteristic of the SW vents during two working days in June 2009. As an extreme example of this type of behaviour, a Type 0 explosion 
Fig. 4 Ground deformation of the NE1 vent shows that, cycles of inflation-deflation may last several minutes. Each plot displays the temporal evolution of grey levels in the videos along a vertical line crossing the vent (red line, about $3 \mathrm{~m}$ long, on the left-hand still-frames). Inflation accelerates nonlinearly a few seconds before an explosion (top inset)

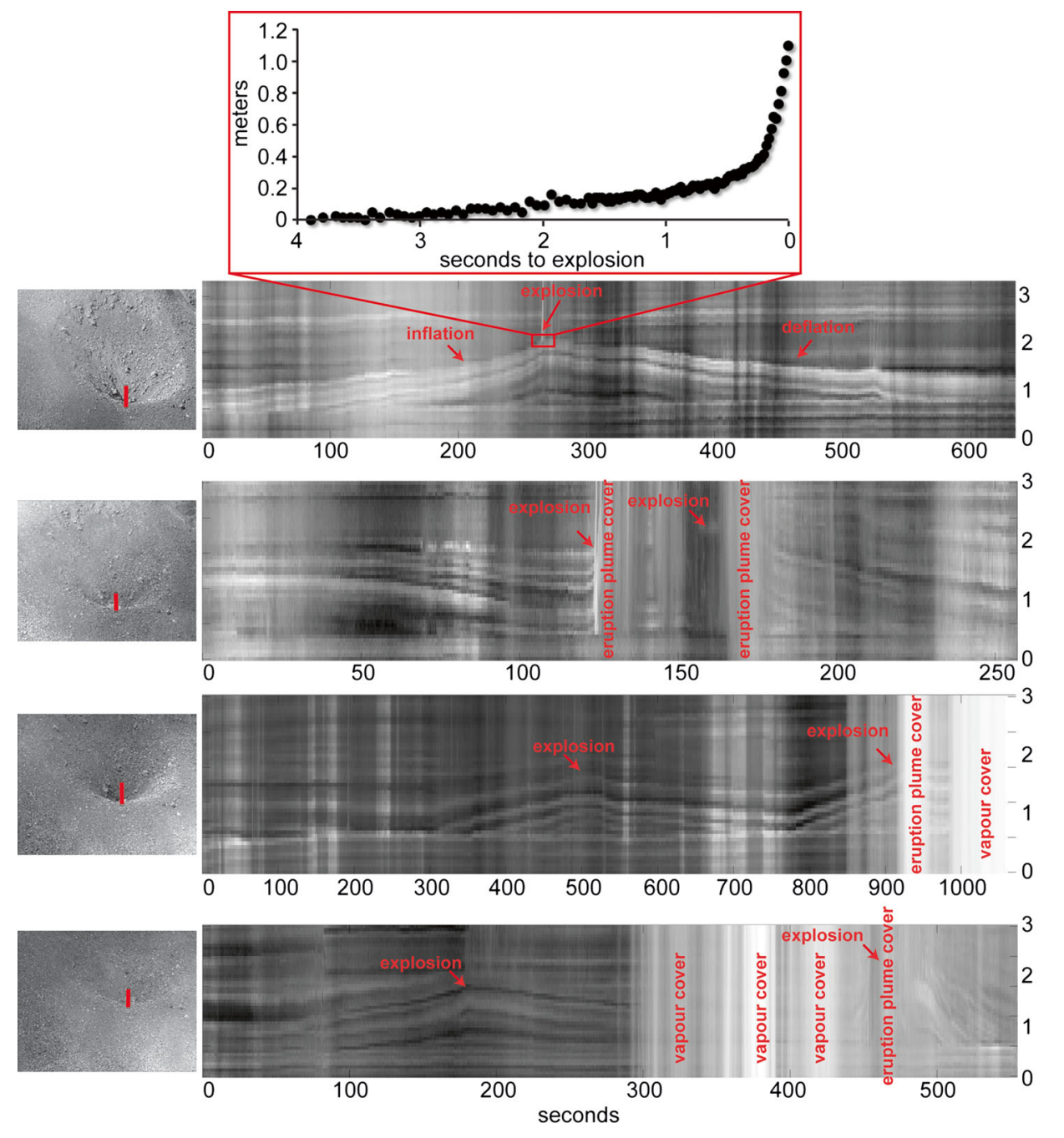

occurred on May 24, 2013, from a metre-sized, glowing, round hole in the SW vent area, with the ejection of relatively few lapilli-sized ejecta, and attained pyroclast velocities of $498 \pm 19 \mathrm{~m} / \mathrm{s}$.

\section{Intermediate and transitional cases}

In several cases, the incandescent surface of the top of the magma column was visible in the vent partially covered by blocks and lapilli from previous explosions. In the very first seconds of an explosion, this surface was disrupted by the bursting of variable sized gas bubbles, which reworked the debris without cleaning-out the vent, until-but not always - a more energetic pulse cleared the vent (Video 7). Individual reworked blocks, when finally ejected, often showed coexisting hot and cold surfaces. In the study cases, bubbling of the surface lasted from $\sim 4$ to $\sim 7 \mathrm{~s}$. The first pulse was followed by an increase in the bubble-burst number and occurrence rate, until pyroclast ejection became almost continuous with multiple pulses and sub-pulses. As in previous cases, spatter was ejected and fell back into the vent, or become plastered onto the inner crater walls, to be recycled by the following pulses. The angles of the jet axes in the main pulses varied widely, between $\sim 90$ and $\sim 45^{\circ}$.

In several cases, two adjacent vents in the SW crater (SW1 and SW2) were observed to erupt simultaneously (Figs. 6 and 9): one was clearly covered by fine particles and was characterized first by degassing (Fig. 9b), then by ash emission (Fig. 9c); the second was partially obscured and involved ballistic-dominated and ash-free emission (Fig. 9b-c). Explosions lasted from $\sim 15$ up to $56 \mathrm{~s}$ and were characterized by low peak velocities, with a maximum just of $29 \pm 1 \mathrm{~m} / \mathrm{s}$. In all cases, velocity time series showed several distinct decay trends lasting $0.2-1 \mathrm{~s}$.

\section{Discussion}

Based on visual features, we identified two end-member conditions of the volcanic vents producing Strombolian 
Fig. 5 Vents with a fine-grained debris cover: explosion at the SW1 vent (a). When a finegrained debris cover is breached, a mixture of ash and coarse pyroclasts is released (b). A substantial amount of fine material falls back into the vent (c), followed by a new, weaker emission of ash and coarse pyroclasts $(\mathbf{d})$

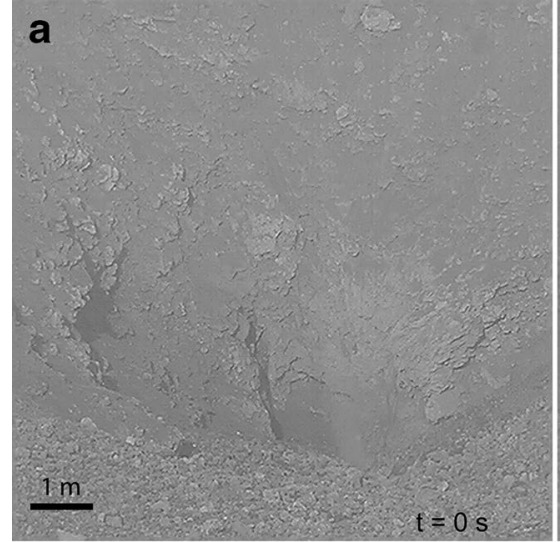

b
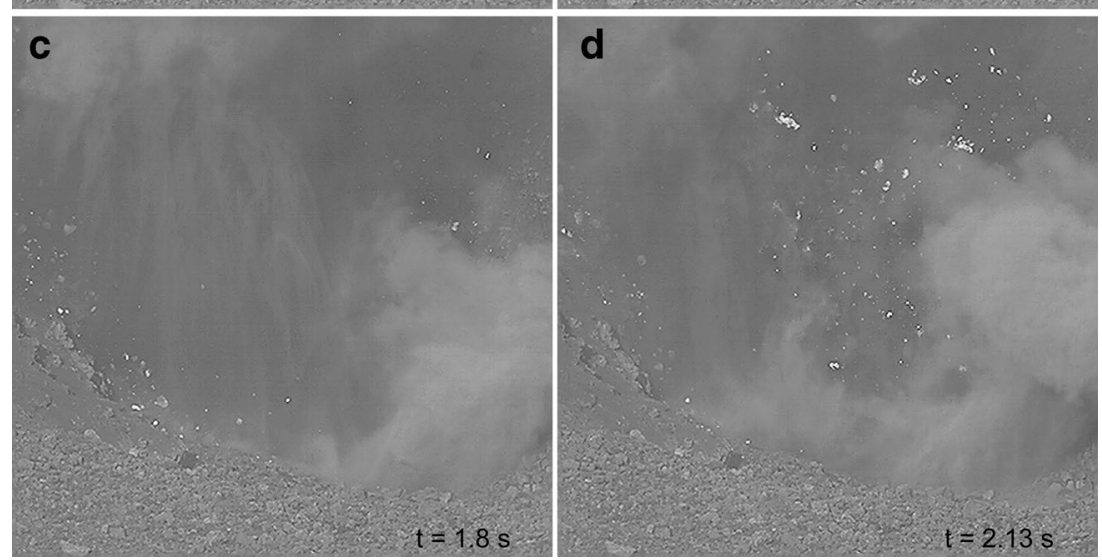

explosions, i.e. clogged vs. open vents, which seem to have affected both the style and vigour of the eruptions.

\section{Effect of the cover}

The presence and nature of vent cover has been hypothesized to influence explosion style at Stromboli by Patrick et al. (2007), and more recently by Leduc et al. (2015). Our observations provide the first direct confirmation to this hypothesis. Within our limited number of observations, Type 0 explosions invariably occurred through open vents, Type 1 through open or sparsely covered vents and Type 2 through heavily covered vents. The dynamics of vent cover incorporation in the erupted gas/pyroclast mixture controlled the explosion style (and type). A weak explosion through a coarse-grained debris cover (Fig. 3) would be classified as a bomb-free Type $2 b$ explosion according to Patrick et al. (2007). In this case, weakly overpressured gas may have effectively elutriated only the finer particles from the overall coarse-grained cover. A stronger explosion at the same vent would also mobilize coarser pyroclasts in a bomb-rich Type $2 a$ explosion. Finegrained covers were usually entrained entirely into the plume. A thick, fine-grained cover in a narrow vent can be ejected enmasse, resulting in a small-scale pyroclastic density current (Fig. 6, Video 4) preceding the main explosion.
Several lines of evidence suggest that covered vent explosions are less energetic than open-vent explosions. Covered vent explosions have lower pyroclast ejection velocity and are never associated with visible shock or pressure waves (Taddeucci et al. 2014). Likewise, ash-rich (Type 2) explosions at Mt. Yasur (Vanuatu) are associated with lower acoustic amplitudes than ash-free (Type 1) events (Spina et al. 2015). The presence of a debris cover in the vent may affect the gas behaviour both before its release from the magma (i.e. at fragmentation), when the gas has to lift and dislodge the cover, as well as after fragmentation, when the gas has to either accelerate the debris or percolate through it. Recent experimental investigation shows how the presence of a viscous plug at the top of the magma column acts to increase the pressure at burst of slugs (Del Bello et al. 2015). We found no evidence for such an increase in the presence of cover, which apparently did not affect the growth and pressurization of the gas slugs. This is probably because the debris cover is too weak - as it is unconsolidated - to hinder gas expansion and, thus, increase slug overpressure at burst. Conversely, the presence of cover acted to dampen the energy of the event, because part of the energy stored in the gas overpressure dissipated through percolation and was used in debris acceleration. The final outcome of an explosion thus results from the competition between the amount, coherence and size of the clogging material, and the volume and 
Fig. 6 Selected frames of a thermal video from the SW vent, covering 7':55": landslides (dashed circles, 02':02.177" and $\left.02^{\prime}: 18.517^{\prime \prime}\right)$ and ground deformation (dashed line, $07^{\prime}: 27.988^{\prime \prime}$ ) precede an initial ash emission breaking through the debris cover. Debris collapse triggers a small-scale pyroclastic density current $\left(07^{\prime}: 30.029^{\prime \prime}\right)$.

While the explosion continues, a new ash-free explosion starts from a nearby vent (white arrow, $\left.07^{\prime}: 54.510^{\prime \prime}\right)$

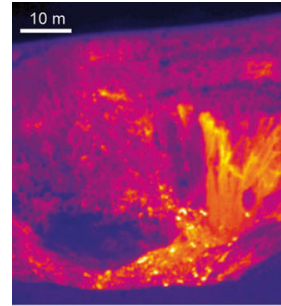

$\mathrm{t}=00$ ':00.000"

reference frame

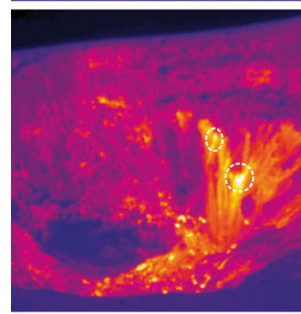

$\mathrm{t}=02^{\prime}: 02.177^{\prime \prime}$

two small landslides occur at the inner crater wall. Debris accumulated at crater bottom
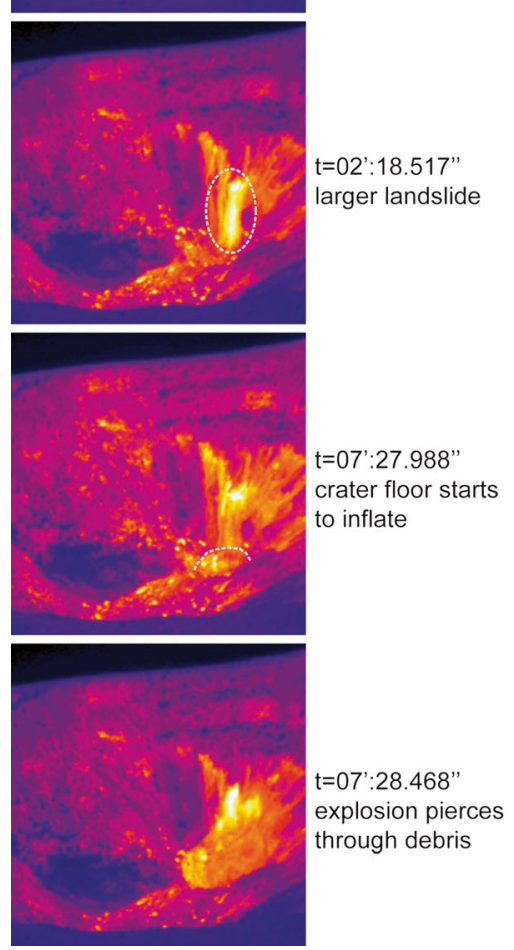

$\mathrm{t}=07^{\prime}: 28.468^{\prime \prime}$ explosion pierces through debris

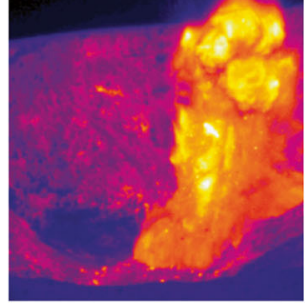

$=07^{\prime}: 29.428^{\prime \prime}$

plume develops while debris collapses

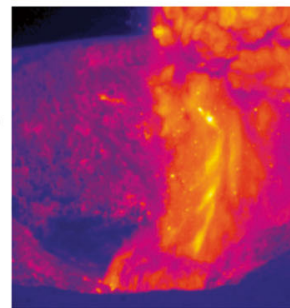

$\mathrm{t}=07^{\prime}: 30.029^{\prime \prime}$

collapsed debris forms

a small pyroclastic

density current while

explosion continues

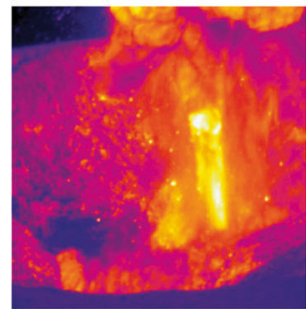

$\mathrm{t}=07^{\prime}: 31.428^{\prime \prime}$

the pyroclastic density current climbs the

inner crater wall while

explosion continues

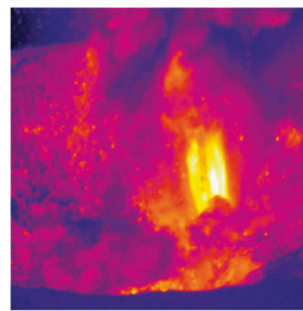

$\mathrm{t}=07^{\prime}: 33.008^{\prime \prime}$

the pyroclastic density

current lifts off the

ground while explosion

continues

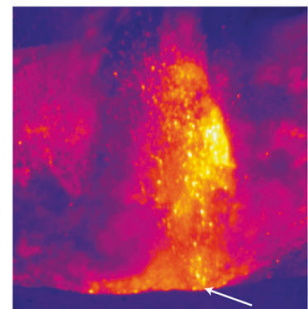

$\mathrm{t}=07^{\prime}: 54.510^{\prime \prime}$

while explosion

continues a new,

ash-free explosion

starts at another vent

close by pressure of the gas slug arriving at the base of the plug. In analogy to other explosive processes, we propose that this competition can be expressed by the scaled depth concept (the thickness of the debris cover divided by the cube root of the stored energy), which has been shown experimentally to control ejecta velocity and pressure wave amplitude (Taddeucci et al. 2013b).

The vertical motion of the debris cover (Fig. 4) could be linked to volumetric changes in the conduit before and after an explosion. These changes occurred in the timescale of hundreds of seconds, which is comparable to the timescale of pre-explosion conduit pressurization recorded by ground motion (Genco and Ripepe 2010), and is also compatible with time scales of bubble rise and growth in a basaltic magma (Nishimura 2009). The accelerating trend of inflation of the debris that we observed in the seconds before an explosion also matched the surface motion of a liquid column hosting a rising, pressurized gas slug (James et al. 2008, 2009). We conclude that, before an explosion, the vent-filling debris is pushed upward by the magma head which, in turn, is rising under the effect of the ascending and expanding gas slug. After the explosion, the remaining debris cover subsides back into the vent. The rate of subsidence could be controlled by the gravitational collapse of the debris into an empty conduit or the gradual sinking of the magma head. Our observations do not allow a conclusive discrimination between the two cases. However, the similar rates of debris inflation and deflation seem more readily explained by gradual magma sinking rather than debris collapse. 
Fig. 7 Open vent: at the NE1 vent (a), a dominant, wellcollimated jet of fast pyroclasts (b) decays rapidly, followed by tens of pulses and sub-pulses that evolve quickly with a wider exit angle (c). Concomitant to the peaks of activity, decimetre-sized, colder recycled clasts (red circles) are ejected (d) and, at the same time, both the eruption rate and exit angle increase
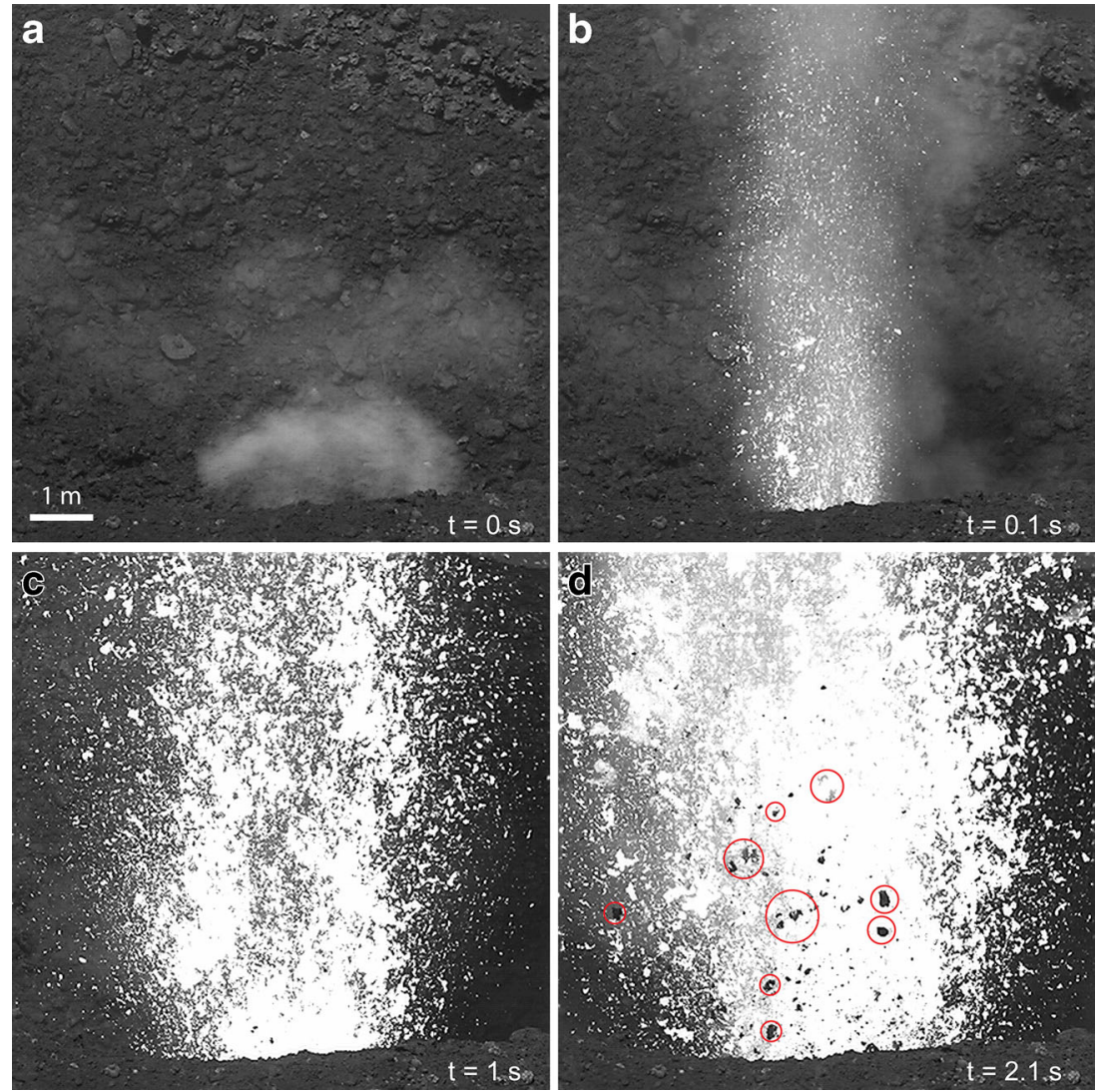

\section{Origin of the cover}

Fallback of pyroclasts into the vent is the prime process for the formation of the debris cover. Pyroclasts were observed to fall back directly from the plume, during or after an explosion, and from the inner flanks of craters, by rolling and sliding (also, ejecta from the NEC have been observed to fall into open vents in SWC: thus, one vent may produce clog material for another one; Andy Harris, personal communication, 2015). Central to the formation of the cover is the relationship between energy and dynamics of the explosions on the one hand, which controls the size, range and trajectory of the pyroclasts, and the morphology of the vent area on the other, which controls pyroclast accumulation and distribution. At the timescale of weeks-months, the two factors are not independent at Stromboli, where periods of more frequent activity are also marked by stronger activity (Taddeucci et al. 2013a). A stronger and more frequent activity implies a wider dispersal of products and higher emission rates, promoting the growth of positive landforms around vent areas and limiting fallback (up to the formation of hornito structures). On the contrary, weaker and less frequent activity implies smaller dispersal of pyroclasts and negligible variations in the vent settings, both favouring debris accumulation, as also speculated by Patrick et al. (2007). At the timescale of hours-days a positive feedback may arise between debris accumulation resulting in weaker explosions, causing reduced ejecta range and, consequently, increasing clast fallback towards the vent. The feedback may be broken by an occasional explosion strong enough to clean the vent. The extreme sensitivity of this feedback to local conditions is well illustrated by cases of two neighbour vents erupting simultaneously but with different styles (Figs. 6 and 9), where minor variations result in different degrees of vent cover and explosion types even at two interconnected vents.

The mechanical and thermal state of the vent cover is open to speculations. For instance, the source of ash in Type 2 explosions could be milling from repeated collisions among coarser clasts over multiple explosions or brittle fragmentation of cooled and crystallized magma, as argued by Patrick et al. (2007). We directly observed milling and fallback of ash into the vents (Figs. 3 and 6). However, we also note that, with respect to coarser pyroclasts, ash was easily wind-advected outside the vent areas, suggesting that an internal source of ash (i.e. magma fragmentation) may be required for prolonged Type 2 activity periods. The presence of degassed and crystallized magma at the top of the Stromboli conduits is well established (e.g. Lautze and Houghton 2006; Gurioli et al. 2014), along with the potential role of clast recycling on its formation (D'Oriano et al. 2014). Indeed, there must be an 

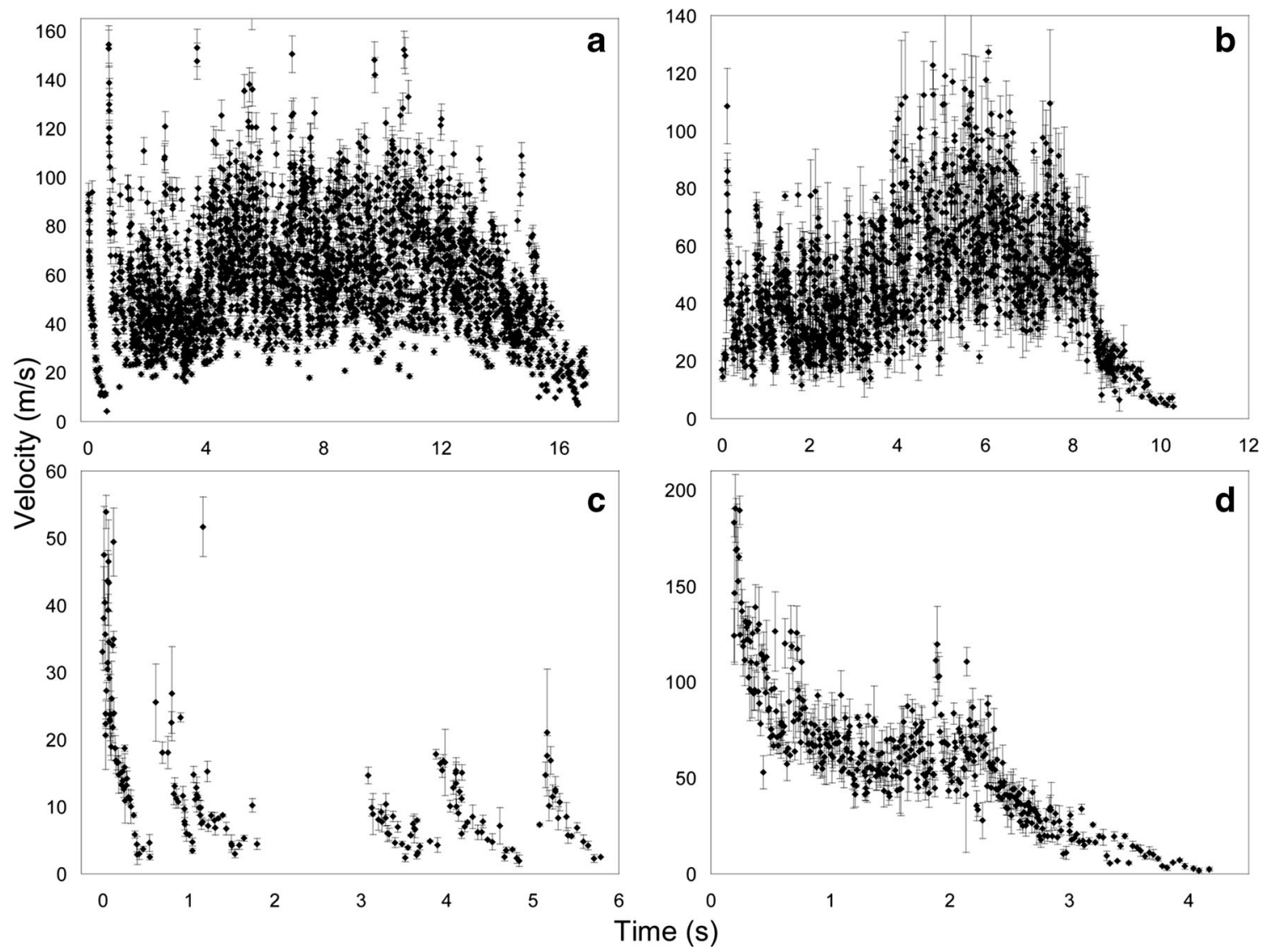

Fig. 8 Examples of ejection velocity of pyroclasts over time for explosions at open vent NE1 (a, b), coarse-cover vent NE2 (c) and fine-cover vent SW1 (d) vent. Each point represents the velocity of a

single centimetre-sized pyroclast, averaged over 4-10 frames. Time $=0$ corresponds to the time at which the first pyroclast is observed

interface, or transition zone, between the degassed layer at the top of the magma column and the debris cover filling the vent (Fig. 1). Direct evidence for this zone is provided by the observed partially molten clasts, and by the high temperature of the ash filling the vent (Fig. 6). The mixing with fallen back debris, due to pre- and post-explosion disruption of the debris cover, would increase the viscosity of the magma residing in the topmost part of the conduit, by enhanced cooling and addition of solids (crystals and

cold scoria fragments), thus promoting its brittle behaviour and fine fragmentation.

\section{Conclusions}

High-speed observations of vent activity at Stromboli show how open vent vs. debris-clogged vent conditions affect the style of explosive activity. The debris cover forms by
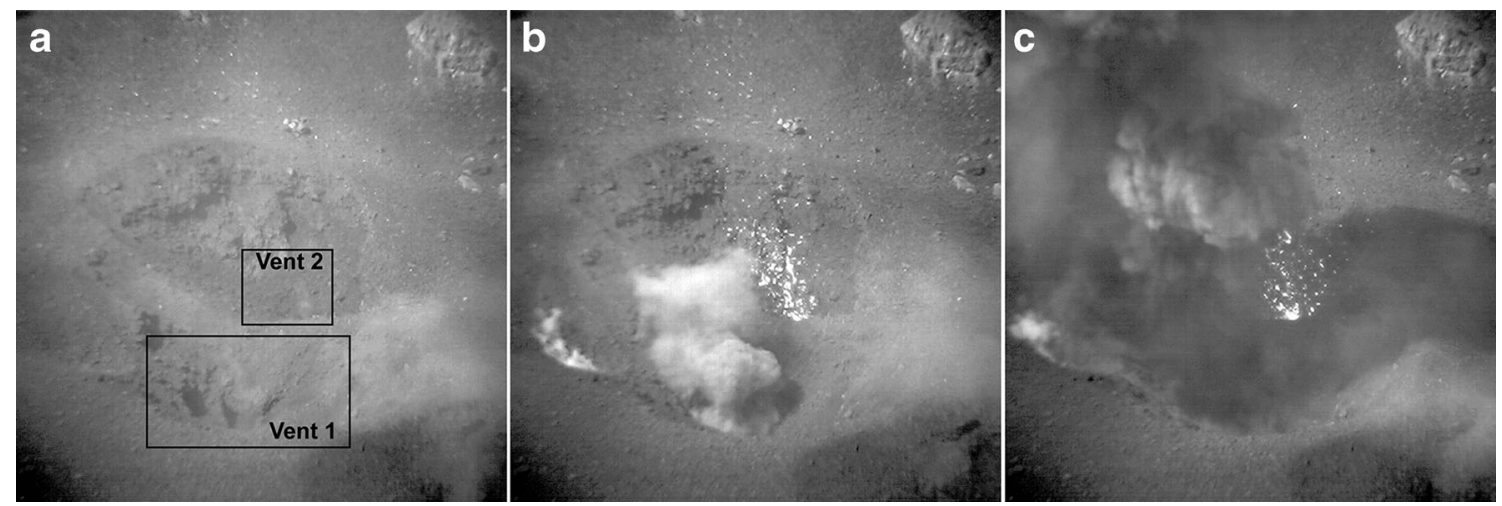

Fig. 9 SW1 and SW2 vents (a), showing different eruptive styles during simultaneous activities: SW1 is characterized by degassing (b) and ash emission (c), while SW2 shows ballistic-rich and ash-free explosions (b-c) 
accumulation of pyroclasts into the vent by fallback and rolling/sliding along the inner crater walls, controlled by the interplay of frequency and intensity of the explosions. The effects of the vent cover can be summarized as follows:

1. with respect to explosions at open vents, clogged vents feature the ejection of slower (and colder) pyroclasts, the presence of a debris cover effectively dampening and slowing down the gas expansion process;

2. for debris-covered vents, explosion dynamics are sensitive to the amount and grain size distribution of the debris: while Type $2 a$ explosions are observed mainly from vents with fine-grained cover, weaker Type $2 b$ explosions occur through vents with a coarse-grained cover. This observation confirms previous hypothesis on the origin of different explosion types (e.g. Patrick et al. 2007; Leduc et al. 2015);

3. metre-scale vertical motions of the debris cover precede (inflation) and follow (deflation) explosions on a timescale of tens of minutes, paralleling motions of the magma head. The rise rate of the debris cover is compatible with that expected for the rise and expansion of a pressurized gas slug towards the top of the magma column;

4. the debris cover is observed to thermally and mechanically interact with the magma at the top of the conduit, possibly resulting in cooling and increased viscosity, in turn promoting brittle, finer fragmentation of the top magma layer.

The observed phenomena show how the presence and nature of debris cover may lead to complex eruptive dynamics, by affecting gas expansion, eruption intensity, grain size distribution and ejection velocity of erupted material. These findings need to be considered and integrated in future models to better understand how the interaction among arriving gas slugs, a possible viscous plug and a near-surface debris cover controls explosion style and vigour.

Acknowledgments A.C. was funded by MIUR (Ministry of Education, University and Scientific Research of Italy) grant "Parameterizing the Dynamics of Strombolian Eruptions through High-Speed Video Analysis" and, as part of his PhD at Lancaster University, from the People Programme (Marie Curie Actions) of the European Union's Seventh Framework Programme (FP7/2007-2013) under the project NEMOH, REA grant agreement $n^{\circ} 289976$. We are indebted with U. Kueppers, E. Del Bello, Zazà, and all other colleagues, friends, and scecchi who helped us in the many field campaigns at Stromboli. We thank journal reviewers Matt Patrick and Andy Harris, and associate Editor Pierre-Simon Ross for thorough and constructive comments that greatly improved the manuscript.

Open Access This article is distributed under the terms of the Creative Commons Attribution 4.0 International License (http:// creativecommons.org/licenses/by/4.0/), which permits unrestricted use, distribution, and reproduction in any medium, provided you give appropriate credit to the original author(s) and the source, provide a link to the Creative Commons license, and indicate if changes were made.

\section{References}

Abramoff MD, Magelhaes PJ, Ram SJ (2004) Image processing with ImageJ. Biophotonics Int 11:36-42

Barberi P, Rosi M, Sodi A (1993) Volcanic hazard assessment at Stromboli based on review of historical data. Acta Vulcanol 3: 173-187

Blackburn EA, Wilson L, Sparks RSJ (1976) Mechanisms and dynamics of strombolian activity. J Geol Soc. doi:10.1144/gsjgs.132.4.0429

Bombrun MA, Harris A, Gurioli L, Battaglia J, Barra V (2015) Anatomy of a Strombolian eruption: inferences from particle data recorded with thermal video. J Geophys Res. doi:10.1002/2014JB011556

Burton MR, Mader HM, Polacci M (2007) The role of gas percolation in quiescent degassing of persistently active basaltic volcanoes. Earth Planet Sci Lett. doi:10.1016/j.eps1.2007.08.028

Cashman KV, Sparks RSJ (2013) How volcanoes work: a 25 year perspective. Geol Soc Am Bull 125:664-690

Chouet B, Hamisevicz N, McGetchin TR (1974) Photoballistics of volcanic jet activity at Stromboli, Italy. J Geophys Res 79:4961-4976

Chouet B, Dawson P, Ohminato T, Martini M, Saccorotti G, Giudicepietro F, De Luca G, Milana G, Scarpa R (2003) Source mechanisms of explosions at Stromboli Volcano, Italy, determined from moment-tensor inversions of very-long-period data. J Geophys Res. doi:10.1029/2002JB001919

Chouet B, Dawson P, Martini M (2008) Shallow-conduit dynamics at Stromboli Volcano, Italy, imaged from waveform inversions. In: Lane SJ, Gilbert JS (Eds.), Fluid Motions in Volcanic Conduits: A Source of Seismic and Acoustic Signals. Geol Soc, London, Special Publications, 307:57-84

Colò L, Ripepe M, Baker DR, Polacci M (2010) Magma vesiculation and infrasonic activity at Stromboli open conduit volcano. Earth Planet Sci Lett. doi:10.1016/j.eps1.2010.01.018

D’Oriano C, Bertagnini A, Pompilio M (2011) Ash erupted during normal activity at Stromboli (Aeolian Islands, Italy) raises questions on how the feeding system works. Bull Volcanol. doi:10.1007/s00445010-0425-0

D’Oriano C, Bertagnini A, Cioni R, Pompilio M (2014) Identifying recycled ash in basaltic eruptions. Sci Rep. doi:10.1038/srep05851

Del Bello E, Lane SJ, James MR, Llewellin EW, Taddeucci J, Scarlato P, Capponi A (2015) Viscous plugging can enhance and modulate explosivity of strombolian eruptions. Earth Planet Sci Lett. doi:10. 1016/j.epsl.2015.04.034

Gaudin D, Taddeucci J, Scarlato P, Moroni M, Freda C, Gaeta M, Palladino DM (2014) Pyroclast Tracking Velocimetry illuminates bomb ejection and explosion dynamics at Stromboli (Italy) and Yasur (Vanuatu) volcanoes. J Geophys Res Sol-Ea. doi:10.1002/ 2014JB011096

Genco R, Ripepe M (2010) Inflation-deflation cycles revealed by tilt and seismic records at Stromboli volcano. Geophys Res Lett. doi:10. 1029/2010GL042925

Gurioli L, Colò L, Bollasina AJ, Harris AJL, Whittington A, Ripepe M (2014) Dynamics of strombolian explosions: inferences from field and laboratory studies of erupted bombs from Stromboli volcano. J Geophys Res Sol-Ea. doi:10.1002/2013JB010355

Harris AJL, Ripepe M (2007) Synergy of multiple geophysical approaches to unravel explosive eruption conduit and source dynamics - a case study from Stromboli. Chemie der Erde - Geochemistry 67:1-35

Harris AJL, Ripepe M, Hughes EA (2012) Detailed analysis of particle launch velocities, size distributions and gas densities during normal explosions at Stromboli. J Volcanol Geoth Res. doi:10.1016/j. jvolgeores.2012.02.012

Houghton BF, Gonnermann HM (2008) Basaltic explosive volcanism: constraints from deposits and models. Chemie der Erde Geochemistry. doi:10.1016/j.chemer.2008.04.002 
James MR, Lane SJ, Chouet B, Gilbert JS (2004) Pressure changes associated with the ascent and bursting of gas slugs in liquid-filled vertical and inclined conduits. J Volcanol Geoth Res 129:61-82

James MR, Lane SJ, Chouet BA (2006) Gas slug ascent through changes in conduit diameter: Laboratory insights into a volcano-seismic source process in low-viscosity magmas. J Geophys Res. doi:10. 1029/2005JB003718

James MR, Lane SJ, Corder SB (2008) Modelling the rapid near-surface expansion of gas slugs in low viscosity magmas. Geol Soc London Spec Pub. doi:10.1144/SP307.9

James MR, Lane SJ, Wilson L, Corder SB (2009) Degassing at low magma-viscosity volcanoes: quantifying the transition between passive bubble-burst and Strombolian eruption. J Volcanol Geotherm Res. doi:10.1016/j.jvolgeores.2008.09.002

Lane SJ, James MR, Corder SB (2013) Volcano infrasonic signals and magma degassing: first-order experimental insights and application to Stromboli. Earth Planet Sci Lett. doi:10.1016/j.epsl. 2013.06.048

Lautze NC, Houghton BF (2005) Physical mingling of magma and complex eruption dynamics in the shallow conduit at Stromboli volcano. Italy Geology. doi:10.1130/G21325.1

Lautze NC, Houghton BF (2006) Linking variable explosion style and magma textures during 2002 at Stromboli volcano. Italy Bull Volcanol. doi:10.1007/s00445-006-0086-1

Leduc L, Gurioli L, Harris A, Colò L, Rose-Koga EF (2015) Types and mechanisms of strombolian explosions: characterization of a gasdominated explosion at Stromboli. Bull Volcanol. doi:10.1007/ s00445-014-0555-5

Marchetti E, Ripepe M (2005) Stability of the seismic source during effusive and explosive activity at Stromboli Volcano. Geophys Res Lett. doi:10.1029/2004GL021406

McGetchin TR, Settle M, Chouet BA (1974) Cinder cone growth modeled after Northeast Crater, Mount Etna, Sicily. J Geophys Res 79:3257-3272

Meijering E, Dzyubachyk O, Smal I (2012) Methods for cell and particle tracking. Methods Enzymol 504:183-200

Nishimura T (2009) Ground deformation caused by magma ascent in an open conduit. J Volcanol Geotherm Res. doi:10.1016/j.jvolgeores. 2009.09.001

Parfitt EA (2004) A discussion of the mechanisms of explosive basaltic eruptions. J Volcanol Geother Res. doi:10.1016/j.jvolgeores.2004. 01.002

Patrick MR, Harris AJL, Ripepe M, Dehn J, Rothery DA, Calvari S (2007) Strombolian explosive styles and source conditions: insights from thermal (FLIR) video. Bull Volcanol. doi:10.1007/s00445006-0107-0
Ripepe M, Rossi M, Saccorotti G (1993) Image processing of explosive activity at Stromboli. J Volcanol Geotherm Res 54:335-351

Ripepe M, Harris AJL, Marchetti E (2005) Coupled thermal oscillations in explosive activity at different craters of Stromboli volcano. Geophys Res Lett. doi:10.1029/2005GL022711

Rosi M, Bertagnini A, Landi P (2000) Onset of the persistent activity at Stromboli Volcano (Italy). Bull Volcanol. doi:10.1007/ s004450000098

Spina L, Taddeucci J, Cannata A, Gresta S, Lodato L, Privitera E, Scarlato P, Gaeta M, Gaudin D, Palladino DM (2015) Explosive volcanic activity at Mt. Yasur: a characterization of the acoustic events (912th July 2011). J Volcanol Geother Res. doi:10.1016/j.jvolgeores. 2015.07.027

Taddeucci J, Scarlato P, Capponi A, Del Bello E, Cimarelli C, Palladino DM, Kueppers U (2012a) High-speed imaging of Strombolian explosions: the ejection velocity of pyroclasts. Geophys Res Lett. doi: 10.1029/2011GL050404

Taddeucci J, Alatorre-Ibargüengoitia MA, Moroni M, Tornetta L, Capponi A, Scarlato P, Dingwell DB, De Rita D (2012b) Physical parameterization of Strombolian eruptions via experimentallyvalidated modelling of high-speed observations. Geophys Res Lett. doi:10.1029/2012GL052772

Taddeucci J, Palladino DM, Sottili G, Bernini D, Andronico D, Cristaldi A (2013a) Linked frequency and intensity of persistent volcanic activity at Stromboli (Italy). Geophys Res Lett. doi:10.1002/GRL. 50652

Taddeucci J, Valentine GA, Sonder I, White JDL, Ross P-S, Scarlato P (2013b) The effect of pre-existing craters on the initial development of explosive volcanic eruptions: an experimental investigation. Geophys Res Lett. doi:10.1002/grl.50176

Taddeucci J, Sesterhenn J, Scarlato P, Stampka K, Del Bello E, Pena Fernandez JJ, Gaudin D (2014) High-speed imaging, acoustic features, and aeroacoustic computations of jet noise from Strombolian (and Vulcanian) explosions. Geophys Res Lett. doi:10.1002/ 2014GL059925

Taddeucci J, Edmonds M, Houghton B, James MR, Vergniolle S (2015) Hawaiian and Strombolian eruptions. In: Sigurdsson H, Houghton B, Rymer H, Stix J, McNutt S (eds) The encyclopedia of volcanoes, 2nd edn. Academic Press, Amsterdam, pp 485-503

Vergniolle S, Brandeis G, Mareschal JC (1996) Strombolian explosions 2. Eruption dynamics determined from acoustic measurements. J Geophys Res 101:449-466

Washington HS (1917) Persistence of vents at Stromboli and its bearing on volcanic mechanism. G Soc Am B 28:249-278 